\title{
All about Prisms- Easy to Understand
}

\section{Partha Haradhan Chowdhury ${ }^{1 *}$ and Brinda Haren Shah ${ }^{2}$}

1M. Optom, Department of Optometry, Shree Satchandi Jankalyan Samiti Netra

Prasikshan Sansthan, Pauri, Affiliated to Uttarakhand State Medical Faculty, India

${ }^{2}$ M. Optom, Department of Optometry, Gujarat University, India

Short Communication

Volume 3 Special Issue 1

Received Date: July 06, 2018

Published Date: July 20, 2018

*Corresponding author: Partha Haradhan Chowdhury, M. Optom, Department of Optometry, Shree Satchandi Jankalyan Samiti Netra Prasikshan Sansthan, Pauri, Affiliated to Uttarakhand State Medical Faculty, Dehradun, India, Email: optometrypublish@gmail.com

\section{Abstract}

This paper describes about introduction to prisms used in ophthalmology, its optics and its calculation.

Keywords: Prism; Prentice Rule; Risley Prism

\section{Introduction}

Prism is defined as a portion of transparent, non parallel, isotropic material and two polished surface. Usually it is helpful for making all ophthalmic lenses and it is very helpful for vergence also.

Ophthalmic prisms have mild curved surface and the meaning of isotropic is "from the area of the prism, have equal amount of scattering effect" is present. The prism consists of Apex or Apical Angle and Base. Whenever the light is passing through the prism, then light is bend towards the Base and image will be shifted towards the Apex. Apex is denoted in degrees and whatever the light is passing through the prism that is denoted with $\mathrm{cm}$ [1-3].

So, the Prism Diopter can be defined as "A deviation of 1 $\mathrm{cm}$ at a distance of $1 \mathrm{~m}$ " $1 \mathrm{PD}=0.57$ degrees

All the ophthalmic lenses are made up of prisms, so if spherical lenses are decentered from its proper position then it can create prismatic effect. It is explained by "Prentice Rule."

$$
\mathrm{P}=\mathrm{D}^{*} \mathrm{~F}
$$

Where D is Decentration and F is Refractive Power of the lens.

\section{Basic Instruction for Prentice Rule}

In case of minus refractive error, base direction will be opposite compared to decentration of spherical lens.

In case of plus refractive error, base direction will be on the same side compared to decentration of spherical lens.

Always $\mathrm{mm}$ should be converted to $\mathrm{cm}$.

Eg :

a) If , spherical lens is -8.00 Ds and decentration is $5 \mathrm{~mm}$ towards nose, then according to prentice rule,

$$
\mathrm{P}=\mathrm{D} * \mathrm{~F}
$$

$5 \mathrm{~mm}=0.5 \mathrm{~cm}$ (mm should be converted to $\mathrm{cm}$ )

$\mathrm{P}=0.50 *(-8.00)$

$=4.0$ PD Base out.

Here, base direction towards ear became decentration towards nose, opposite due to minus lens.

b) If, spherical lens is +9.00 Ds and decentration is $4 \mathrm{~mm}$ towards nose, then as per prentice rule,

$0.4^{*}(+9.00)$

$$
\mathrm{P}=\mathrm{D} * \mathrm{~F}
$$

$=3.6$ PD Base In 


\section{Open Access Journal of Ophthalmology}

Here, base direction is on the same side compare to decentration due to plus lens.

\section{Risley Prisms}

$\mathrm{R}=$ Risley prism

$\mathrm{R}=$ Rotary prism

This prism is used in Refractor/ Phoropter, to measure phoria and fusional vergence. Risley prism consists of two prisms, one behind the other. It consists of a knob, when the knob is oriented vertically, then Base in prism and
Base out prism is imposed, when knob is oriented horizontally, then Base up and Base down prism is imposed.

\section{References}

1. Atchison DA, Smith G (2005) Optics of the Human Eye.

2. Fannin TE, Grosvenor TP (1996) Clinical Optics.

3. Benjamin WJ (2006) Borish's Clincial Refraction.

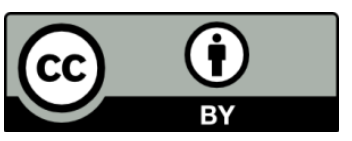

